\title{
Perspectives of Nanotechnology in Minimally Invasive Therapy of Breast Cancer
}

\author{
Yamin Yang and Hongjun Wang* \\ Chemistry, Chemical Biology and Biomedical Engineering, Stevens Institute of \\ Technology, Hoboken, NJ 07030, USA
}

Submitted September 2012. Accepted for publication November 2012.

\begin{abstract}
Breast cancer, the most common type of cancer among women in the western world, affects approximately one out of every eight women over their lifetime. In recognition of the high invasiveness of surgical excision and severe side effects of chemical and radiation therapies, increasing efforts are made to seek minimally invasive modalities with fewer side effects. Nanoparticles $(<100 \mathrm{~nm}$ in size) have shown promising capabilities for delivering targeted therapeutic drugs to cancer cells and confining the treatment mainly within tumors. Additionally, some nanoparticles exhibit distinct properties, such as conversion of photonic energy into heat, and these properties enable eradication of cancer cells. In this review, current utilization of nanostructures for cancer therapy, especially in minimally invasive therapy, is summarized with a particular interest in breast cancer.
\end{abstract}

Keywords: breast cancer, minimally invasive therapy, nanoparticles

\section{INTRODUCTION}

Breast cancer is the most common type of cancer among women in the western world, which affects approximately one out of every eight women over their lifetime. According to the most recent estimates for breast cancer from the American Cancer Society, about 226,870 women are diagnosed with invasive breast cancer, and more than 39,000 will die from it every year in the United States [1]. Despite tremendous efforts in search for alternative treatments, surgical excision, chemotherapy and radiation currently still remain the primary options for breast cancer, with surgical excision biopsy as the gold standard diagnostic modality [2]. However, these treatment practices are either invasive with a high risk of morbidity or accompanied with severe side effects (e.g., hair loss, fatigue, etc.) [3]. Recognition of these associated challenges has greatly motivated efforts in exploring other therapies with minimal invasion, which

*Corresponding author: Hongjun Wang, PhD, Department of Chemistry, Chemical Biology and Biomedical Engineering, Stevens Institute of Technology, McLean Building Room 416, Castle Point on Hudson, Hoboken, NJ 07030, USA. Phone: (201) 216-5556. Fax: (201) 216-8240. E-mail: Hongjun.Wang@ stevens.edu. Other author: yyang8@stevens.edu. 
can not only shorten the patient recovery time but also cause less morbidity and fewer complications. With the continuous progress in mammography screening for early detection of small-sized breast cancer lumps, minimally invasive therapy has become more practical and popular than ever [4-6] .

Recent progress in nanotechnology (referring to structures less than $100 \mathrm{~nm}$ in size) has shed exciting light on cancer therapy and diagnosis due to the large surface area, high surface reactivity and unique physicochemical properties of these nanostructures [7-9]. Cumulative evidence has shown the advantages of nanoparticles in cancer therapy, in which nanoparticles can be engineered to incorporate various chemotherapeutics and deliver them to a specific tumor site for better efficacy and less toxicity in chemotherapy [10-15]. Moreover, the tunable size and surface properties can prevent the opsonization of nanoparticles to prolong the circulation, thus increasing the opportunity to accumulate in cancer [16-20]. More details in nanoparticle-assisted drug delivery can be found in several seminal reviews [21-23].

The intrinsic features of nanoparticles hold tremendous promise for their application in minimally invasive therapies. As recognized, the major challenges of current minimally invasive therapy are the unsatisfactory treatment effectiveness and limited targeting capacity [4-6]. One way to address these challenges is to distinguish diseased tissue from healthy tissue while maintaining sufficient killing efficiency with the assistance of nanoparticles. Various nanoparticles, such as liposomes [24-26], dendrimer [27, 28], and magnetic [29, 30] and metallic nanoparticles [31, $32]$, are being evaluated for their potentials in minimally invasive therapies as they have been applied in other cancer therapies. These nanoparticles offer superior advantages, such as increased delivery of cytotoxic drugs, (e.g., doxorubicin [33, 34], paclitaxel [35], oxaliplatin [36], etc.), contrasting agents (e.g., gadolinium containing contrast agents [37] and iron platinum [38], etc. ), or therapeutic gene sequence (e.g., p53 gene [39] and small interfering RNA (siRNA) [40], etc.) to cancer cells (See Figure 1).

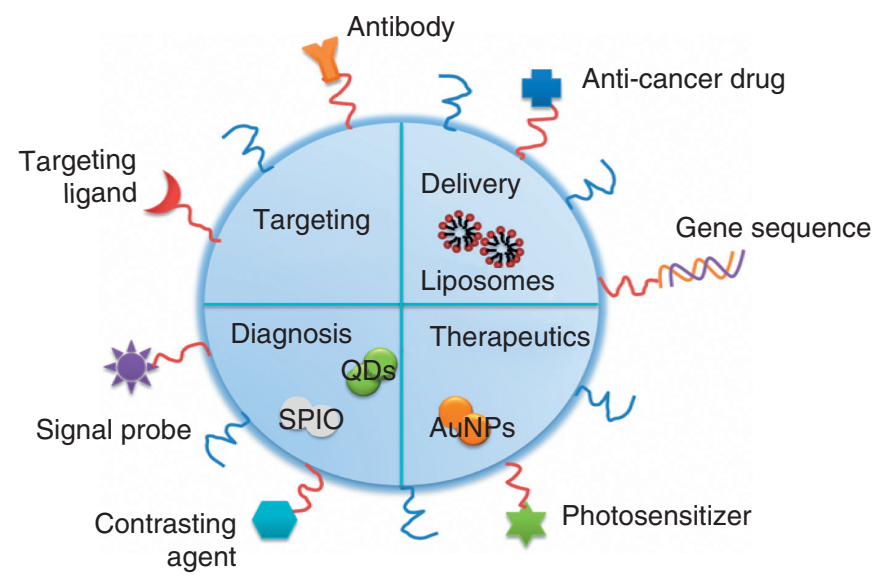

Figure 1. Applications of nanoparticles in cancer treatment. 
Upon modification with tumor-specific ligands (e.g., transferrin receptor [41], herceptin which binds to HER2/neu receptor [42, 43], and folic acid [44], etc.), nanoparticles could be selectively directed to cancer cells, resulting in accumulation of drugs/agents in cancer cells for targeted treatment. In addition to delivering cytotoxic or biologic agents, some nanoparticles themselves act as anticancer therapeutic agents as a result of their unique inherent optical and dielectric properties, magnetic susceptibility, thermal or electrical conductivity. With the continuous evolution of minimally invasive techniques and nanotechnology, their combination will become more intriguing toward future therapeutic interventions of various cancers.

In this review, various minimally invasive therapies for breast cancer will be summarized, with insightful discussion of the advantages and shortcomings of each procedure. We will also discuss the state-of-the-art development of nanotechnology for a variety of minimally invasive modalities with a specific emphasis on their potential contributions.

\section{MINIMALLY INVASIVE TREATMENT OF BREAST CANCER AND NAN- OTECHNOLOGY}

In principle, compared to the standard therapy, minimally invasive therapy for breast cancer could achieve a similar outcome, if not better, with less morbidity, better cosmetic appearance, shorter and safer procedures, quicker recovery and reduced inpatient period for a better quality of life as well as considerable savings in healthcare costs [6]. The most exciting and successful demonstration is the use of percutaneous ablation (i.e., through a small incision on the skin) to eradicate breast cancers instead of surgical excision [45]. To date, four major categories of minimally invasive techniques have been explored for breast cancer treatment, including direct removal (stereotactic excision), tumor ablation through heating or freezing (radiofrequency ablation (RFA), focused ultrasound (FUS) ablation, laser ablation and cryoablation), direct administration of anticancer drugs into tumor site through a catheter (chemoembolization), and light-based therapy (photodynamic and photothermal therapy). Besides removal of the primary tumors, these treatments also show promising results in eradicating residual tumors which still poses a significant recurrence risk to the patient [46]. At present, the main challenges associated with these treatments are to identify the exact tumor location, confine the treatment to tumor and completely destroy tumor cells inside the primary lesion. As noted, inadequate therapeutic efficacy of these minimally invasive approaches results in a high tendency for local recurrence of the cancer [47]. Although the possibility of damage to surrounding healthy tissues of these minimally invasive therapies is much lower than that of conventional therapies, accurately targeting the treatment to tumors is always highly desired to minimize unwanted side effects and improve treatment efficacy. In the following subsections of this review, we will discuss several minimally invasive ablative modalities, including radiofrequency ablation (RFA), focused ultrasound (FUS) ablation, cryoablation, photodynamic and photothermal therapy for breast cancer and potential utilization of nanoparticles in each procedure (see Table 1). 
Table 1. Potential utilization of nanoparticles in minimally invasive techniques for cancer therapy

\begin{tabular}{|c|c|c|c|}
\hline $\begin{array}{l}\text { Treatment } \\
\text { modality }\end{array}$ & $\begin{array}{l}\text { General } \\
\text { mechanism }\end{array}$ & $\begin{array}{l}\text { Nanomaterials } \\
\text { applied }\end{array}$ & $\begin{array}{l}\text { Functions of } \\
\text { nanomaterials }\end{array}$ \\
\hline $\begin{array}{l}\text { Radiofrequency } \\
\text { ablation (RFA) }\end{array}$ & $\begin{array}{l}\text { Heat generated by } \\
\text { an alternating high- } \\
\text { frequency electric } \\
\text { current }\end{array}$ & - Au NPs [48, 49] & $\begin{array}{l}\text { - Targeting cancerous } \\
\text { cells } \\
\text { - Excellent conductor } \\
\text { of thermal energy } \\
\text { - Increased intracellular } \\
\text { heat when exposed to } \\
\text { the external RF field }\end{array}$ \\
\hline $\begin{array}{l}\text { Focused ultrasound } \\
\text { (FUS) ablation }\end{array}$ & $\begin{array}{l}\text { Heat converted from } \\
\text { acoustic energy }\end{array}$ & $\begin{array}{l}\text { - Magnetite }\left(\mathrm{Fe}_{3} \mathrm{O}_{4}\right) \\
\text { nanoparticle } \\
\text { agglomerates [50] } \\
\text { - } \mathrm{Fe}_{3} \mathrm{O}_{4} \text {-containing PLGA } \\
\text { microcapsules [51] }\end{array}$ & $\begin{array}{l}\text { - Enhanced inertial } \\
\text { cavitation } \\
\text { - Enhanced therapeutic } \\
\text { efficacy } \\
\text { - Imaging for guidance }\end{array}$ \\
\hline Cryoablation & $\begin{array}{l}\text { Rapid cooling } \\
\text { achieved by liquid } \\
\text { nitrogen or argon } \\
\text { gas delivered to the } \\
\text { cancer tissue }\end{array}$ & $\begin{array}{l}\text { - Iron oxide magnetite } \\
\left(\mathrm{Fe}_{3} \mathrm{O}_{4}\right) \text { and } \\
\text { maghemite }\left(\gamma-\mathrm{Fe}_{2} \mathrm{O}_{3}\right) \\
{[52]} \\
\text { - TNF- } \alpha \text { gold } \\
\text { nanoparticles [53] }\end{array}$ & $\begin{array}{l}\text { - Enhanced heat } \\
\text { conduction } \\
\text { - Serving as } \\
\text { nucleation seeds } \\
\text { for ice-ball formation } \\
\text { and orientation }\end{array}$ \\
\hline $\begin{array}{l}\text { Photodynamic } \\
\text { therapy (PDT) }\end{array}$ & $\begin{array}{l}\text { Light irradiation for } \\
\text { photosensitizer } \\
\text { activation and } \\
\text { reactive oxygen } \\
\text { species (ROS) } \\
\text { production to destroy } \\
\text { cancerous cells }\end{array}$ & $\begin{array}{l}\text { - p-THPP loaded PLGA } \\
\text { nanoparticles [54] } \\
\text { - ZnPc loaded PLGA } \\
\text { nanoparticles [55] } \\
\text { - Ceramic-based } \\
\text { nanoparticles [56] } \\
\text { - Phthalocyanine- } \\
\text { nanoparticle } \\
\text { conjugates [57] } \\
\text { 5-ALA conjugated } \\
\text { Au NPs [58, 59] }\end{array}$ & $\begin{array}{l}\text { - Selective and } \\
\text { effective delivery } \\
\text { of photosensitizer } \\
\text { - Strong scattering } \\
\text { light energy } \\
\text { - Enhanced localized } \\
\text { electromagnetic } \\
\text { field }\end{array}$ \\
\hline $\begin{array}{l}\text { Photothermal } \\
\text { therapy (PTT) }\end{array}$ & $\begin{array}{l}\text { Electronic excitation } \\
\text { under laser } \\
\text { irradiation and energy } \\
\text { relaxation leading } \\
\text { to overheating } \\
\text { the local } \\
\text { environment }\end{array}$ & $\begin{array}{l}\text { - EGFR-conjugated } \\
\text { Au NPs [60] } \\
\text { - gold-silica } \\
\text { nanoshells [61] } \\
\text { - anti-HER2-conjugated } \\
\text { silica-gold } \\
\text { nanoshells [62] } \\
\text { - PEG-protected gold } \\
\text { nanorods [63] } \\
\text { - folate-single-walled } \\
\text { carbon nanotubes [64] }\end{array}$ & $\begin{array}{l}\text { - Enhanced targeting } \\
\text { specificity } \\
\text { - Strong light } \\
\text { absorption } \\
\text { - High } \\
\text { photostability } \\
\text { - High optical } \\
\text { absorbance in the } \\
\text { near-infrared region }\end{array}$ \\
\hline
\end{tabular}




\subsection{Radiofrequency Ablation}

RFA involves the procedure to insert a radiofrequency (RF) probe with needle-like electrodes to apply alternating electrical current into the breast tumor under imaging guidance such as ultrasound, computed tomography (CT), or magnetic resonance (MR). Heat generated by the alternating high-frequency (e.g., 400 500 kHz) electric current between the electrodes can destroy breast tumor tissue through coagulative necrosis of cancer cells (Figure 2a). Tumor tissue is killed immediately at a temperature exceeding $50-60^{\circ} \mathrm{C}$, while an adequate period of time is needed to kill the tumor if the temperature is just above approximately $40^{\circ} \mathrm{C}$ [65]. The sustainability of the heat depends on the tumor size. During the procedure, the temperature can be monitored by thermometers installed on the electrodes.

RFA ablation is well studied for ablative treatment of breast cancer. Mirza et al. [66] have shown the efficiency of RFA as a local treatment option for breast cancers smaller than $2 \mathrm{~cm}$, that up to $87 \%$ ablation was achieved among 30 breast cancer patients without major complications. Similarly, Izzo et al. [67] also demonstrated a complete ablation and necrosis of breast tumors up to $3 \mathrm{~cm}$ for 25 out of 26 patients after ultrasound-guided RFA.

It appears that RFA is oncologically safe in the short term and yields satisfactory cosmetic outcomes. However, several limitations are also identified in RFA [49], including 1) the need to insert needle electrodes directly into the tumor site for the treatment, indicating their applicability only to those visible tumors; 2) the $3-3.5 \mathrm{~cm}$ maximum tumor size for complete tumor destruction, leading to $5-40 \%$ incomplete destruction for those tumors larger than 4-5 cm; and 3) the nondifferential treatment between malignant and normal tissues by the RF current around the needle electrode, increasing the risk of complications as a result of the thermal injury to normal tissue. Increasing the voltage of RF can enlarge the treatment area; however, it also produces extra heat inducing more complications. To address the last two limitations, the RF-toheat conversion needs to be more efficient with RF-induced heating preferably limited to tumor cells.

Further improvement of the RF-to-heat conversion and confinement of the RFA only to tumors require the assistance of agents that can increase the thermal effects under RF radiation and be directed to the malignant cells. Among various agents, nanoparticles

(a)

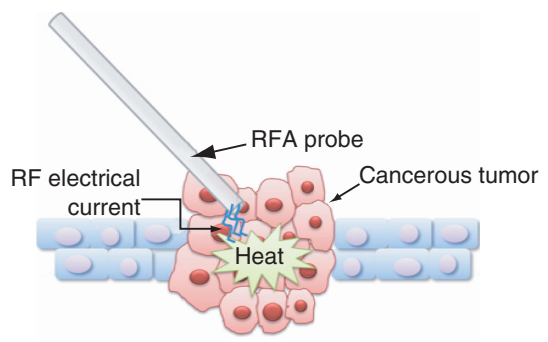

(b)

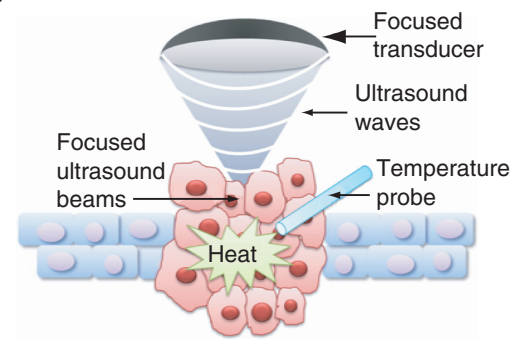

Figure 2. Diagrammatic illustration of a) radiofrequency ablation (RFA) and b) focused ultrasound (FUS) ablation. 
are considered as promising candidates to achieve the multifunctions, and gold nanoparticles (Au NPs) are of particular interest due to their easy modification with binding molecules to target cancer cells and outstanding electrical and thermal conductivity besides the superior biocompatibility and physical/chemical/biological stability [68-71]. Au NPs internalized by cells can significantly elevate the intracellular heat level upon exposure to an external RF field as evidenced in various settings. For example, Gannon et al. [49] demonstrated that Au NPs $(\sim 5 \mathrm{~nm})$ released substantial heat after exposure to a high-voltage focused RF field $(13.56 \mathrm{MHz})$ and its dosedependent lethal injury to human cancer cells (Hep3B cells and Panc-1 cells) was more than $96 \%$. Cardinal et al. [48] also found that the presence of $13 \mathrm{~nm}$ Au NPs in HepG2 liver cancer cells induced adequate heat to raise the temperature $\left(>50^{\circ} \mathrm{C}\right)$ and caused approximately $80 \%$ cell death upon exposure to $13.56 \mathrm{MHz}$ RF field ( $35 \mathrm{~W}$ for $7 \mathrm{~min}$ ). Additional evidence was also shown in their in vivo experiments of the same study, in which the injection of Au NPs into JM-1 hepatoma nodule-bearing Fisher rats resulted in a significant increase of local temperature and thermal injury to the subcutaneous injection sites upon exposure to $35 \mathrm{~W}$ RF field compared to the sham controls without $\mathrm{Au}$ NPs. To better guide the Au NPs into breast cancer cells, an appealing approach is to modify the Au NPs with breast-cancer-specific ligand, HER-2, and then via the ligand-receptor interaction, Au NPs could be endocytosed by HER-2-expressing breast cancer cells $[72,73]$.

\subsection{Focused Ultrasound Ablation}

Minimally invasive tumor ablation through thermal effects can also be achieved by Focused Ultrasound (FUS). After localization of the tumor within the breast, ultrasound can be focused to rapidly generate substantial heat by converting the acoustic energy from an ultrasonic source. The slow heat dissipation leads to the increase of local temperatures up to $90^{\circ} \mathrm{C}$, which can cook the tumor and cause the necrosis of cells and ablation of tumors [74] (Figure 2b). Temperature is monitored by probes during the FUS-induced tumor ablation process. It is possible to focus the ablation on a small lesion with high-resolution imaging techniques such as MRI for accurate detection and monitoring [75, 76]. For breast cancer treatment, Gianfelice et al. [77] used MRIguided FUS to treat 12 patients with metastatic breast tumors smaller than $3.5 \mathrm{~cm}$. Up to $88.3 \%$ of the tumor tissue was ablated with no major complications.

The major advantage of FUS is that no skin incision is required during the treatment. However, the difficulty for ultrasound to penetrate through air and bone results in its relatively low therapeutic efficiency for deep tumor lesions. Since ultrasound energy attenuates with the depth of the tissue, high power ultrasounds are needed for those deep tumors, which could cause severe side effects such as skin burns and nerve injury $[78,79]$. Achieving a high therapeutic efficiency at a low acoustic power remains to be an unmet challenge in FUS therapy [51]. Magnetite nanoparticles have held great promise to address this challenge in consideration of their capability of enhancing inertial cavitation induced by high-intensity focused ultrasound (HIFU). Ho et al. [50] reported that with the presence of $\mathrm{Fe}_{3} \mathrm{O}_{4}$ nanoparticle agglomerates, 50\% duty cycle of focused ultrasound was sufficient to cause cell lysis and to disintegrate the whole Hela spheroid. Instead of using pure magnetite particles, Sun et al. [51] introduced an 
organic/inorganic hybrid system based on $\mathrm{Fe}_{3} \mathrm{O}_{4}$-containing poly(lactic-co-glycolic acid) (PLGA) microcapsules $\left(\mathrm{Fe}_{3} \mathrm{O}_{4} / \mathrm{PLGA}\right.$ ) to enhance the HIFU therapeutic efficacy with a simultaneous MRI/ultrasound dual biological imaging modality for HIFU guidance. The experimental results demonstrated that utilization of these composite microcapsules could efficiently improve ultrasonography and magnetic resonance imaging of cancer both in vitro and in vivo, and significantly enhance the HIFU ablation of breast cancer in tumor-bearing rabbits. Besides magnetite nanoparticles, Choi et al. [80] recently designed Gd-C5F12-phospholipid nanobubbles (PLNs, 30-100 nm in diameter) to enhance the hyperthermal effect of HIFU. The Gd-C5F12-PLNs have a prolonged plasma half-life in mice (longer than $1.5 \mathrm{hrs}$, about three times longer than that of SonoVue), and consequently extend the circulation time of PLNs-encapsulated HIFU agents. The long circulation time provides a window for the agent to accumulate in tumor tissues that have highly permeable, angiogenic microvessels. Indeed, GdC5F12-PLNs monitored by T1-weighted MR imaging continuously increased in the tumor tissues (colon cancer cell line CT-26) of BALB/c nude mice until at least 4 hrs after intravenous injection via the tail vein. HIFU treatment with Gd-C5F12-PLNs ablated a significantly larger tumor area than no HIFU or HIFU alone. The results suggest that Gd-C5F12-PLNs exhibit theragnostic potential for MR-guided HIFU ablation. Despite the advantages of Gd-C5F12-PLNs in enhancing HIFU ablation, some issues need to be carefully addressed prior to clinical application: 1) inertial cavitation due to combining HIFU and gas-filled Gd-C5F12-PLNs is unpredictable and may cause complications; 2) the effect of HIFU-induced hyperthermia on Gd chelation of the nanobubbles needs to be well studied to assure no release of free Gd with toxicity.

\subsection{Cryoablation}

In contrast to the above thermal-based ablation, cryoablation (cryosugery) is another approach to achieve minimally invasive, controlled destruction of tumor tissues through a specifically administered freezing procedure (Figure 3). During this procedure, one or

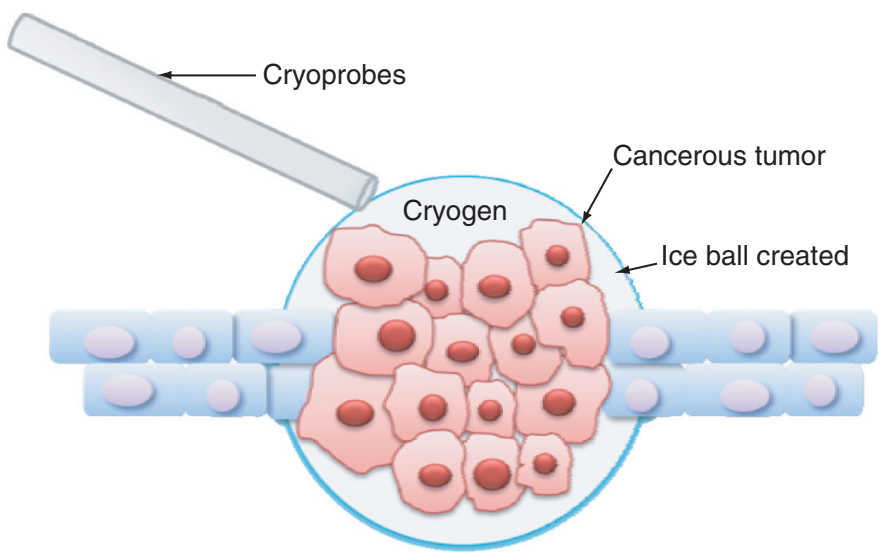

Figure 3. Diagrammatic illustration of cryoablation. 
more small needles, called cryoprobes, deliver either liquid nitrogen or argon gas directly to the cancer tissue. Cellular damage is believed to result from the disruption of cell membrane during the freeze/thaw cycles. Imaging guidance based on ultrasound, $\mathrm{CT}$, or MRI is needed to direct the cryoprobes to the right location. The ablated area can be easily visualized under the ultrasound since the ice ball formed during the therapy is hypoechoic [81]. For more details in probes, cryogens, major mechanisms of cellular, vascular injury and possible immunological effects due to freeze-thaw treatment, Goel et al. [82] have made a fascinating summary.

Currently, cryoablation is still in its experimental stage for breast cancer treatment. Its long-term effectiveness remains to be determined and is now under investigation. Sabel et al. [83] reported the only clinical trial on cryoablation of breast cancer, in which twenty-seven patients with ultrasound-visible primary invasive breast cancer $(\leq 2.0 \mathrm{~cm})$ successfully underwent ultrasound-guided cryoablation with a double freeze/thaw cycle using a tabletop argon-gas-based cryoablation system under local anesthesia. Complete ablation was successfully achieved for tumors less than $1 \mathrm{~cm}$, but only $63 \%$ of tumors larger than $1 \mathrm{~cm}$ were completely ablated, indicating suitability of cryoablation for early-stage breast cancer.

There are several practical concerns regarding cryosurgery for breast tumor treatment. The most important one is that insufficient or inappropriate freezing may not completely destroy the tumor and lead to tumor regenesis, thus failing treatment. Meanwhile, the surrounding healthy tissue may suffer from freezing injury. Cryoablation is a localized therapy and only treats the disease at a single site. Sonographic monitoring may be inaccurate to estimate the exact dimensions of the iceball and some microscopic cancer may be missed during the treatment [83].

With enhanced thermal conductivity and capability to serve as nucleation seeds, certain nanoparticles can be combined with cryosurgical procedures to increase treatment efficacy [52, 84]. Moreover, nanoparticles modified with tumor-specific ligands can target tumor tissues for treatment accuracy [52, 84]. It is expected that the presence of nanoparticles in cryoablation can maximize the freezing heat transfer process, regulate freezing scale, modify the orientation of iceball formation and prevent the surrounding healthy tissues from being frozen. In addition, the introduction of nanoparticles during cryosurgery could also help to visualize the edge of a tumor as well as the margin of the iceball for better positioning of the treatment [52].

Nanoparticles suitable for cryoablation can be made from a variety of materials including inorganic metals, biodegradable polymers, liposomes, micelles, semiconductors, etc. [52]. Yan et al. [52] claimed that iron oxide, magnetite $\left(\mathrm{Fe}_{3} \mathrm{O}_{4}\right)$ and maghemite $\left(\gamma-\mathrm{Fe}_{2} \mathrm{O}_{3}\right)$, nanoparticles with high thermal conductivity and good biological compatibility might be a popular and appropriate choice for enhancing freezing rate with controllable iceball formation. In cryosurgery, the destruction of cancer within the iceball is normally incomplete. To solve this issue, Goel et al. [82] have tried to deliver tumor necrosis factor- $\alpha$ (TNF- $\alpha$ ) to the human prostate carcinoma xenografts in nude mice using 30-nm Au NPs for enhancing the destruction within an iceball. The results suggest that pre-incubation with TNF- $\alpha$ conjugated Au NPs can efficiently destroy tumor cells within the iceball and cause more shrinkage of the tumor without systemic toxicity. Although 
comprehensive studies are needed to further elaborate the effects of nanomaterials on cryosurgery, it is believed that the nanoparticle-enabled maximization of the freezing rate as well as in vivo medical imaging could be the promising future of cryosurgery [84].

\subsection{Photodynamic Therapy}

Photodynamic therapy (PDT) has been developed as a modality for cancer treatment, which combines the use of low energy light with a photosensitizer. A photosensitizer is a chemical compound that can be excited by visible or near-infrared (NIR) light of a specific wavelength. Usually, the photosensitizer is activated from a ground singlet state to an excited singlet state and is followed by a longer-lived triplet state. When the photosensitizer and an oxygen molecule are in proximity, energy can be transferred to the oxygen molecule, leading to the generation of reactive singlet oxygen species. Singlet oxygen species will ultimately cause the apoptosis or necrosis of tumor cells $[85,86]$ (Figure 4a).

The initial clinical application of PDT was mainly in the treatment of superficial lesions such as skin cancer, superficial epidermal lesions, and superficial mucosal lesions etc. in consideration of the limited penetration of light and photosensitizer [87, 88]. Currently, efforts are underway to extend the PDT to other types of cancers including breast cancer. Various photosensitizers (e.g., 5-aminolaevulinic acid and mitoxantrone) have been assessed for their effectiveness in mediating the destruction of breast cancer cells under light irradiation $[89,90]$. Ahn et al. [89] reported an in vivo PDT study using BALB/c mouse models with subcutaneous EMT6 mammary carcinomas. Their findings confirmed that PDT with a moderate energy of $90 \mathrm{~J} / \mathrm{cm}^{2}$ could be used to treat breast cancers less than $10 \mathrm{~mm}$.

PDT has shown multifaceted advantages like low morbidity, minimum functional disturbance, good tolerance, and the ability to be applied to the same site repeatedly. However, the major limitation of PDT comes from the shortcomings of conventional photosensitizers, e.g., high lipophilicity, poor selectivity, and the need for a large amount to obtain sufficient killing efficiency. In addition, the limited penetration of laser to tumor tissue also impacts the efficacy of PDT, especially in the situation of breast cancer. In general, the efficiency of PDT is largely determined by 1) the

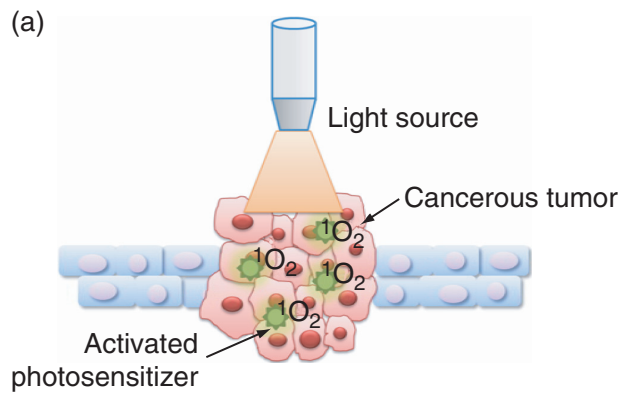

(b)

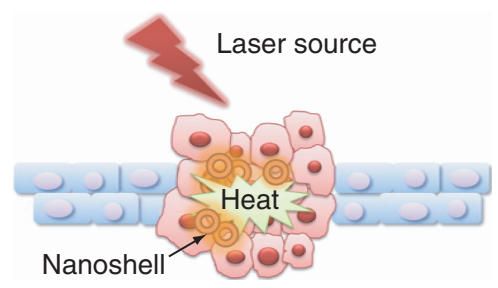

Figure 4. a) Photodynamic therapy (PDT) and b) photothermal therapy (PTT). 
therapeutic concentration of photosensitizer that is delivered to the diseased site, 2) the light dose that is absorbed, 3) the oxygen level in the tissue, and 4) the specificity of singlet oxygen formation in targeted tissues. While much attention has been paid to improve light sources, selectively enhancing the light absorbance by photosensitizers in the cancerous cells can be another interesting approach to increasing PDT efficiency.

In search for possible improvement of PDT efficiency, nanoparticles hold favorable solutions to address at least one of the aforementioned issues. Various strategies have been tried to use nanoparticles as the photosensitizer carrier for passively or actively delivering the photosensitizers to tumor tissues by converting the hydrophobic photosensitizer into cell-permeable hydrophilic format or choosing the appropriate size. In a review from Chatterjee et al. [90], the emerging application of various nanoparticles for PDT has been comprehensively summarized. Functionally, nanoparticles can be used as a passive carrier in PDT to simply carry the photosensitizer around. Both polymer-based and non-polymer-based nanoparticles have been tested for this purpose [91-94]. Selective accumulation of the photosensitizer-loaded nanoparticles in cancer cells can be achieved via surface modification of the nanoparticles with those molecules (e.g., monoclonal antibodies [95, 96]) targeting cancer cells. Instead of merely serving as a carriage for photosensitizer, some nanoparticles participate in the actual PDT process. For instance, Au NPs, which are widely used in cancer detection and treatment, can enhance PDT as a result of their unique optical properties (i.e., surface plasmonic resonance). As shown in Figure 5, briefly, upon electromagnetic enhancement, the light absorbed onto the surface of $\mathrm{Au}$ NPs is scattered and transferred to the neighboring photosensitizer molecule. Due to the plasmonic enhancement by Au NPs, more photosensitizer molecules are activated, consequently increasing the formation of singlet oxygen species. Therefore, Au NPs can enhance the PDT killing efficiency. In our previous study, elevated formation of

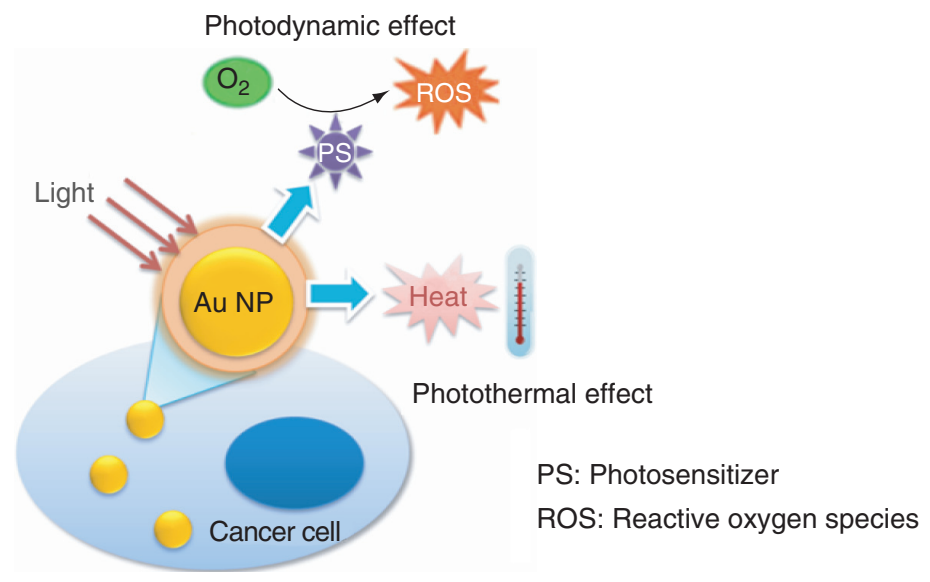

Figure 5. Basic mechanism underlying Au-NP-assisted photodynamic and photothermal reactions. 
reactive oxygen species (ROS) was detected on fibrosarcoma tumor cells treated with 5-aminolevulinic acid (ALA)-conjugated Au NPs, leading to 50\% more cell death compared to those treated with 5-ALA alone [58]. Recently, we have further demonstrated that $\mathrm{Au}$ NPs can significantly promote ROS formation with protoporphyrin IX (PpIX) photosensitizer upon light irradiation. The convergence of experimental findings and theoretical simulation on size-dependent ROS formation and plasmonic enhancement suggests that elevated generation of ROS in the presence of $\mathrm{Au}$ NPs is attributed to highly localized plasmonic resonance fields on Au NP surface, which increased with particle size [59]. Following the similar mechanism, other gold nanostructures such as nanorods [97-99] and nanoshells [100] can also be used in PDT to enhance ROS formation.

\subsection{Photothermal Therapy}

An alternative to PDT is photothermal therapy (PTT), in which photothermal agents are employed to achieve a selective heating of the local tissue (Figure 4b). Upon absorbing photons, PTT agents are excited from their ground state to an excited state. Different from PDT where energy is transferred to oxygen molecule, excited PTT agents release vibrational energy (i.e., heat) (Figure 4b), consequently increasing the local temperature. Ideally, PTT should induce an elevated temperature within cancerous tissue while avoiding overheating the surrounding healthy tissue. However, currently available hyperthermia modalities are often unable to selectively target the tumor tissue without collateral organ damage [101]. In this regard, photoabsorbing nanostructures have been developed in order to enhance both photothermal effects and improved specificity in cancer treatment in conjunction with lasers in the NIR region [102]. These nanostructure agents include noble metal nanoparticles (e.g., hollow gold nanoshells, gold nanorods, gold nanocages), titanium nanotubes, photothermal-based nanobubbles, polymeric nanoparticles and copper-based nanocrystals, etc.

Noble metal nanoparticles have become widely adopted agents for PTT on account of their enhanced absorption cross sections, usually four to five orders of magnitude larger than those of conventional photoabsorbing dyes. The strong absorption ensures effective laser therapy at a relatively lower power to render a minimal invasion. Additionally, the high photostability of metal nanostructures warrants no photobleaching. Currently, gold nanospheres, gold nanorods and gold nanoshells have been demonstrated as photothermal therapeutics for their strong absorption in the visible and NIR regions from the surface plasmon resonance (SPR) oscillations [61]. In addition to the localized SPR properties, the highly functionalizable surface of gold nanostructures can be conjugated with versatile molecules such as antibodies, polymers, or DNA to increase the targeting specificity [91-93].

Various studies have revealed that gold-silica nanoshells release a significant amount of heat when exposed to NIR light $(650-950 \mathrm{~nm})$ and have been used to produce thermal cytotoxicity both in vitro and in vivo [54, 103, 104]. Recently, El-Sayed et al. [60] demonstrated the use of epidermal growth factor receptor (EGFR)-conjugated Au NPs as a photothermal agent, which can specifically target cancer cells overexpressing EGFR. It was found that malignant cells required less than half the laser energy to be 
killed than benign cells under the same exposure conditions. This Au NP-mediated photothermal cancer therapy presents a promising treatment option for chemotherapy resistant cancers. For example, Carpin et al. [62] demonstrated that anti-HER2conjugated silica-gold nanoshells can mediate the effective targeting and photothermal ablation of two HER2-expressing breast cancer cell lines, which are both resistant to treatment with trastuzumab. Besides nanoshells, efforts were also made to use Au NPs or nanorods in PTT [63, 105, 106]. Maltzahn et al. [63] synthesized polyethylene glycol (PEG)-protected gold nanorods (PEG-NR) that exhibited better spectral bandwidth and photothermal heat generation than gold-silica nanoshells, showing great potential for ultraselective tumor ablation. They found that PEG-NR rapidly generated more than 6 times of heat generated by PEG-gold nanoshells under identical experimental conditions, and can cause more efficient destruction of human tumor cells (MDA-MB435) after light irradiation. In vivo study showed that intravenous injection of PEG-NRs enabled destruction of human xenograft tumors in mice upon irradiation. Besides noble metal nanoparticles, Hong et al. [107] demonstrated the potential therapeutic effect of titanium oxide nanotubes $\left(\mathrm{TiO}_{2} \mathrm{NTs}\right)$ for cancer therapy with both in vitro cell and in vivo animal (CT-26 murine colon carcinoma tumor bearing mice) tests. They found that $\mathrm{TiO}_{2}$ NTs in combination with NIR laser could destroy all tumor cells without damaging surrounding healthy tissue under optimized the treatment conditions in terms of laser intensity, laser exposure time, amount of $\mathrm{TiO}_{2} \mathrm{NTs}_{\text {suspension and } \mathrm{TiO}_{2} \mathrm{NTs}}$ concentration. Single-walled carbon nanotubes (SWNTs) with a high optical absorbance in the NIR region were also investigated for selective photothermal therapy of cancer [64, 108]. Zhou et al. [64] found that folate-SWNTs effectively enhanced the photothermal destruction of tumor cells by $980-\mathrm{nm}$ laser irradiation while noticeably sparing non-targeted normal cells in both in vitro and in vivo experiments. However, negative reports on the biosafety of SWNT raise some concerns on their clinical application [109, 110].

\section{DISCUSSION AND PERSPECTIVES}

The advent and advancement of nanotechnology has shed promising light on both cancer therapy and diagnostics. In particular, the high surface/volume ratios, deep tissue penetration, versatile surface chemistry for modification, and distinct optical and magnetic properties have empowered nanoparticles with potentials to enhance the efficacy of many minimally invasive therapies for breast cancer. It is envisioned that if nanoparticles can be directed only to cancer cells, treatment efficacy would be more pronounced and specific. This is especially crucial for those therapies with detrimental side effects. For example, in nanoparticle-assisted PTT, one critical challenge is to control the extent of thermal intervention only necessary to kill the tumor [111]. Unfortunately, thus far, there are no available strategies that are effective enough to guide nanoparticles only into cancer cells, even with the conjugation of cancer cell specific ligands like HER-2 [112]. Addition of excess targeting ligands also increases the clearance rate by mononuclear phagocyte system. Therefore, it is still uncertain how active targeting affects nanoparticle accumulation in targeted tissues. The effect of nanoparticle size and ligand density on cellular uptake and tumor targeting remains to 
be further established in order to improve the nanoparticle design for optimal tumor accumulation [113]. In pursuing a better targeting strategy, limited understanding of the interactions between cells and nanoparticles has left several key questions unanswered and targeting unsolved. The questions include, e.g., What is the system distribution of nanoparticles through different administration routes? What is the fate of the nanoparticles following therapy? How fast can nanoparticles travel into cells? All these questions may be complicated by the versatility of nanoparticles in size, surface properties, and shape on one hand, and the presence of various molecules and selfprotecting filtration systems in vivo on the other hand. The proper answers to these questions are essential to address the targeting issue [114].

Besides the properties of nanoparticles, more attention should be paid to their biodistribution and biosafety prior to clinical application. Although many of the materials are safe in bulk with known interaction profile with biological system, such information may not be directly applicable to the nanoscale. As a matter of fact, the small size of nanoparticles allows them to penetrate into tissue and accumulate inside cells, and the large surface area would lead to more interactions between nanoparticles and cells as well as the intracellular organelles [115]. To this end, the evaluation of biosafety and cell/nanoparticle interaction becomes highly demanded and it needs to be investigated in a physiologically relevant setting. For example, Au NPs are known for their biocompatibility without adverse effects [116, 117]. This finding is, however, only valid under low concentration. It was found that Au NPs at high concentrations could significantly slow down cell proliferation with certain cytotoxicity [118]. Obviously, the studies on the interaction between biological system and nanoparticles as well as comprehensive understanding of 1) the cellular uptake mechanism and intracellular destination, 2) biological distribution and clearance, and 3) short- and long-term toxicity of nanomaterials, can help to better design the therapeutic strategy appropriate for minimally invasive therapy. In addition, the insightful understanding of cell and nanoparticle interactions will also formulate the basis to develop new biomarker-probe systems and targeting strategies with optimal particle compositions, geometries, activation, and high payload delivery, which can facilitate the combination of diagnostics with therapeutics in the future.

\section{CONCLUSION}

With concerns of morbidity and severe side effects from established breast cancer therapies, minimally invasive therapy is highly desirable and will continue to evolve at an ever-faster pace as a result of the rapid progress in early diagnosis and the emergence of new technology. The application of nanotechnology in healthcare, though still in its early stage, introduces many potentially exciting and revolutionary solutions to address the unmet challenges confronting current minimally invasive therapy and may lead to the development of new modalities. Besides promising experimental findings in minimally invasive techniques (RFA, FUS, cryoablation, PDT and PTT, etc.), extensive efforts in clinically relevant tests must be conducted prior to their adoption for routine practice especially in breast cancer management. In addition, it remains elusive how various nanostructures are ingested via various 
entry routes (e.g., intravenous injection, inhalation), transported through biological barriers (e.g., the blood barrier), preferentially accumulated in targeted tissues (tumors) and removed from the biological system (e.g., kidney filtration). In this regard, comprehensive understanding of these issues in a physiologic system is crucial for their further clinical utility. Once these issues are solved, multifunctional nanostructures will significantly elevate our capability of diagnosing and yield nextgeneration minimally invasive oncological interventions with high efficiency and specificity.

\section{ACKNOWLEDGEMENT}

Yamin Yang is financially supported by the Innovation \& Entrepreneurship Doctoral Fellowship from Stevens Institute of Technology.

\section{CONFLICT OF INTEREST}

The authors indicated no potential conflicts of interest.

\section{REFERENCES}

[1] What are the key statistics about breast cancer? http://www.cancer.org/cancer/breastcancer/ detailedguide/breast-cancer-key-statistics, Accessed December 05, 2012.

[2] Heneghan HM, Prichard RS, Devaney A, Sweeney KJ, Malone C, McLaughlin R, Kerin MJ. Evolution of breast cancer management in Ireland: a decade of change. BMC surgery, 2009, 9:15.

[3] Loprinzi PD, Cardinal BJ. Effects of physical activity on common side effects of breast cancer treatment. Breast cancer, 2012, 19:4-10.

[4] Noguchi M. Minimally invasive surgery for small breast cancer. Journal of surgical oncology, 2003, 84:94-101.

[5] Singletary SEVA. Minimally invasive techniques in breast. Seminars in Surgical Oncology, 2001, 20(3):246-250.

[6] Hung WK, Ying M, Chan CM, Lam HS, Mak KL. Minimally invasive technology in the management of breast disease. Breast cancer, 2009, 16:23-29.

[7] Brigger I, Dubernet C, Couvreur P. Nanoparticles in cancer therapy and diagnosis. Advanced drug delivery reviews, 2012, 54:631-651.

[8] Choi Y-E, Kwak J-W, Park JW. Nanotechnology for early cancer detection. Sensors, 2010, 10:428-455.

[9] Conde J, Doria G, Baptista P. Noble metal nanoparticles applications in cancer. Journal of drug delivery, 2012, 751075.

[10] Brannon-Peppas L, Blanchette JO. Nanoparticle and targeted systems for cancer therapy. Advanced drug delivery reviews, 2004, 56:1649-1659.

[11] Koo OM, Rubinstein I, Onyuksel H. Role of nanotechnology in targeted drug delivery and imaging: a concise review. Nanomedicine: nanotechnology, biology, and medicine, 2005, 1:193-212.

[12] Sinha R, Kim GJ, Nie S, Shin DM. Nanotechnology in cancer therapeutics: bioconjugated nanoparticles for drug delivery. Molecular cancer therapeutics, 2006, 5:1909-1917.

[13] Kim K, Kim JH, Park H, Kim Y-S, Park K, Nam H, Lee S, Park JH, Park R-W, Kim I-S, Choi K, Kim SY, Park K, Kwon IC. Tumor-homing multifunctional nanoparticles for cancer theragnosis: Simultaneous diagnosis, drug delivery, and therapeutic monitoring. Journal of controlled release, 2010, 146:219-227.

[14] Wang M, Thanou M. Targeting nanoparticles to cancer. Pharmacological research: the official journal of the Italian Pharmacological Society, 2010, 62:90-99. 
[15] Yu MK, Park J, Jeong YY, Moon WK, Jon S. Integrin-targeting thermally cross-linked superparamagnetic iron oxide nanoparticles for combined cancer imaging and drug delivery. Nanotechnology, 2010, 21:415102.

[16] Torchilin VP. Polymer-coated long-circulating microparticulate pharmaceuticals. Journal of microencapsulation, 1998, 15:1-19.

[17] Moore A, Marecos E, Bogdanov A, Weissleder R. Tumoral distribution of iron oxide nanoparticles in a rodent model 1. Radiology, 2000, 214.

[18] Moghimi SM, Hunter a C, Murray JC. Long-circulating and target-specific nanoparticles: theory to practice. Pharmacological reviews, 2001, 53:283-318.

[19] Senthil Kumar P, Pastoriza-Santos I, Rodríguez-González B, Javier García de Abajo F, Liz-Marzán LM. High-yield synthesis and optical response of gold nanostars. Nanotechnology, 2008, 19:015606.

[20] Principe L, D’Arezzo S, Capone A, Petrosillo N, Visca P. In vitro activity of tigecycline in combination with various antimicrobials against multidrug resistant Acinetobacter baumannii. Annals of clinical microbiology and antimicrobials, 2009, 8:18.

[21] Doane TL, Burda C. The unique role of nanoparticles in nanomedicine: imaging, drug delivery and therapy. Chemical Society reviews, 2012, 41:2885-2911.

[22] Waite CL, Roth CM. Nanoscale drug delivery systems for enhanced drug penetration into solid tumors: current progress and opportunities. Critical reviews in biomedical engineering, 2012, 40:21-41.

[23] Ranganathan R, Madanmohan S, Kesavan A, Baskar G, Krishnamoorthy YR, Santosham R, Ponraju D, Rayala SK, Venkatraman G. Nanomedicine: towards development of patient-friendly drug-delivery systems for oncological applications. International journal of nanomedicine, 2012, 7:1043-1060.

[24] Heneweer C, Gendy SEM, Peñate-Medina O. Liposomes and inorganic nanoparticles for drug delivery and cancer imaging. Therapeutic delivery, 2012, 3:645-656.

[25] Kumar P, Gulbake A, Jain SK. Liposomes a vesicular nanocarrier: potential advancements in cancer chemotherapy. Critical reviews in therapeutic drug carrier systems, 2012, 29:355-419.

[26] Namiki Y, Fuchigami T, Tada N, Kawamura R, Matsunuma S, Kitamoto Y, Nakagawa M. Nanomedicine for cancer: lipid-based nanostructures for drug delivery and monitoring. Accounts of chemical research, 2011, 44:1080-1093.

[27] Hu C-MJ, Zhang L. Nanoparticle-based combination therapy toward overcoming drug resistance in cancer. Biochemical pharmacology, 2012, 83:1104-1111.

[28] Kaminskas LM, McLeod VM, Porter CJH, Boyd BJ. Association of chemotherapeutic drugs with dendrimer nanocarriers: an assessment of the merits of covalent conjugation compared to noncovalent encapsulation. Molecular pharmaceutics, 2012, 9:355-373.

[29] Wankhede M, Bouras A, Kaluzova M, Hadjipanayis CG. Magnetic nanoparticles: an emerging technology for malignant brain tumor imaging and therapy. Expert review of clinical pharmacology, 2012, 5:173-186.

[30] Tong L, Zhao M, Zhu S, Chen J. Synthesis and application of superparamagnetic iron oxide nanoparticles in targeted therapy and imaging of cancer. Frontiers of medicine, 2011, 5:379-387.

[31] Dykman L, Khlebtsov N. Gold nanoparticles in biomedical applications: recent advances and perspectives. Chemical Society reviews, 2012, 41:2256-2282.

[32] Cherukuri P, Curley SA. Use of nanoparticles for targeted, noninvasive thermal destruction of malignant cells. Methods in molecular biology, 2010, 624:359-373.

[33] Abbasi S, Paul A, Shao W, Prakash S. Cationic albumin nanoparticles for enhanced drug delivery to treat breast cancer: preparation and in vitro assessment. Journal of drug delivery, 2012, 686108.

[34] Lee S-M, O'Halloran TV, Nguyen ST. Polymer-caged nanobins for synergistic cisplatin-doxorubicin combination chemotherapy. Journal of the American Chemical Society, 2010, 132:17130-17138.

[35] Danhier F, Lecouturier N, Vroman B, Jérôme C, Marchand-Brynaert J, Feron O, Préat V. Paclitaxelloaded PEGylated PLGA-based nanoparticles: in vitro and in vivo evaluation. Journal of controlled release: official journal of the Controlled Release Society, 2009, 133:11-17. 
[36] Yang C, Liu HZ, Fu ZX, Lu WD: Oxaliplatin long-circulating liposomes improved therapeutic index of colorectal carcinoma. BMC biotechnology, 2011, 11:21.

[37] Agrawal P, Strijkers GJ, Nicolay K. Chitosan-based systems for molecular imaging. Advanced drug delivery reviews, 2010, 62:42-58.

[38] Taylor RM, Sillerud LO. Paclitaxel-loaded iron platinum stealth immunomicelles are potent MRI imaging agents that prevent prostate cancer growth in a PSMA-dependent manner. International journal of nanomedicine, 2012, 7:4341-4352.

[39] Xu L, Pirollo KF, Tang WH, Rait A, Chang EH. Transferrin-liposome-mediated systemic p53 gene therapy in combination with radiation results in regression of human head and neck cancer xenografts. Human gene therapy, 1999, 10:2941-2952.

[40] Wu Y, Wang W, Chen Y, Huang K, Shuai X, Chen Q, Li X, Lian G. The investigation of polymersiRNA nanoparticle for gene therapy of gastric cancer in vitro. International journal of nanomedicine, 2010, 5:129-136.

[41] Daniels TR, Bernabeu E, Rodríguez JA, Patel S, Kozman M, Chiappetta DA, Holler E, Ljubimova JY, Helguera G, Penichet ML. The transferrin receptor and the targeted delivery of therapeutic agents against cancer. Biochimica et biophysica acta, 2012, 1820:291-317.

[42] Aydin RST. Herceptin-decorated salinomycin-loaded nanoparticles for breast tumor targeting. Journal of biomedical materials research. Part A, 2012.

[43] Mi Y, Liu X, Zhao J, Ding J, Feng S-S. Multimodality treatment of cancer with herceptin conjugated, thermomagnetic iron oxides and docetaxel loaded nanoparticles of biodegradable polymers. Biomaterials, 2012, 33:7519-7529.

[44] Zhao P, Wang H, Yu M, Liao Z, Wang X, Zhang F, Ji W, Wu B, Han J, Zhang H, Wang H, Chang J, Niu R. Paclitaxel loaded folic acid targeted nanoparticles of mixed lipid-shell and polymer-core: in vitro and in vivo evaluation. European journal of pharmaceutics and biopharmaceutics, 2012, $81: 248-256$.

[45] Fornage BD, Edeiken BS. Percutaneous ablation of breast tumors. Tumor ablation, 2005, 5:428-439.

[46] Salagierski M, Salagierski MS. Radiofrequency Ablation: A Minimally Invasive Approach in Kidney Tumor Management, Cancers. 2010, 2:1895-1900.

[47] Habash RWY, Bansal R, Krewski D, Hafi T. Thermal therapy, Part III: ablation, 2007, 35:37-121.

[48] Cardinal J, Klune JR, Chory E, Jeyabalan G, Kanzius JS, Nalesnik M, Geller DA. Non-invasive radiofrequency ablation of cancer targeted by gold nanoparticles. Surgery, 2008, 144:125-132.

[49] Gannon CJ, Patra CR, Bhattacharya R, Mukherjee P, Curley S. Intracellular gold nanoparticles enhance non-invasive radiofrequency thermal destruction of human gastrointestinal cancer cells. Journal of nanobiotechnology, 2008, 6:2.

[50] Ho VHB, Smith MJ, Slater NKH. Effect of magnetite nanoparticle agglomerates on the destruction of tumor spheroids using high intensity focused ultrasound. Ultrasound in medicine \& biology, 2011, 37:169-175.

[51] Sun Y, Zheng Y, Ran H, Zhou Y, Shen H, Chen Y, Chen H, Krupka TM, Li A, Li P, Wang Z, Wang Z Superparamagnetic PLGA-iron oxide microcapsules for dual-modality US/MR imaging and high intensity focused US breast cancer ablation. Biomaterials, 2012, 33:5854-5864.

[52] Yan J-F, Liu J. Nanocryosurgery and its mechanisms for enhancing freezing efficiency of tumor tissues. Nanomedicine: nanotechnology, biology, and medicine, 2008, 4:79-87.

[53] Goel R, Swanlund D, Coad J, Paciotti GF, Bischof JC. TNF-alpha-based accentuation in cryoinjurydose, delivery, and response. Molecular cancer therapeutics, 2007, 6:2039-2047.

[54] Konan YN, Berton M, Gurny R, Allémann E. Enhanced photodynamic activity of meso-tetra(4hydroxyphenyl)porphyrin by incorporation into sub-200 nm nanoparticles. European journal of pharmaceutical sciences, 2003, 18:241-249.

[55] Ricci-Júnior E, Marchetti JM. Zinc(II) phthalocyanine loaded PLGA nanoparticles for photodynamic therapy use. International journal of pharmaceutics, 2006, 310:187-195. 
[56] Roy I, Ohulchanskyy TY, Pudavar HE, Bergey EJ, Oseroff AR, Morgan J, Dougherty TJ, Prasad PN. Ceramic-based nanoparticles entrapping water-insoluble photosensitizing anticancer drugs: a novel drug-carrier system for photodynamic therapy. Journal of the American Chemical Society, 2003, 125:7860-7865.

[57] Wieder ME, Hone DC, Cook MJ, Handsley MM, Gavrilovic J, Russell D. Intracellular photodynamic therapy with photosensitizer-nanoparticle conjugates: cancer therapy using a "Trojan horse". Photochemical \& photobiological sciences, 2006, 5:727-734.

[58] Kyaw M, Oo K, Yang X, Du H, Wang H. 5-aminolevulinic acid-conjugated gold nanoparticles for photodynamic therapy of cancer. Nanomedicine, 2008, 3(6):777-786.

[59] Khaing Oo MK, Yang Y, Hu Y, Gomez M, Du H, Wang H. Gold nanoparticle-enhanced and sizedependent generation of reactive oxygen species from protoporphyrin IX. ACS nano. 2012, 6:1939-1947.

[60] El-Sayed IH, Huang X, El-Sayed M. Selective laser photo-thermal therapy of epithelial carcinoma using anti-EGFR antibody conjugated gold nanoparticles. Cancer letters, 2006, 239:129-135.

[61] Huang X, Jain PK, El-Sayed IH, El-Sayed M. Plasmonic photothermal therapy (PPTT) using gold nanoparticles. Lasers in medical science, 2008, 23:217-28.

[62] Carpin LB, Bickford LR, Agollah G, Yu T-K, Schiff R, Li Y, Drezek RA. Immunoconjugated gold nanoshell-mediated photothermal ablation of trastuzumab-resistant breast cancer cells. Breast cancer research and treatment, 2011, 125:27-34.

[63] von Maltzahn G, Park J-H, Agrawal A, Bandaru NK, Das SK, Sailor MJ, Bhatia SN. Computationally guided photothermal tumor therapy using long-circulating gold nanorod antennas. Cancer research, 2009, 69:3892-3900.

[64] Zhou F, Xing D, Ou Z, Wu B, Resasco DE, Chen WR. Cancer photothermal therapy in the near-infrared region by using single-walled carbon nanotubes. Journal of biomedical optics, 2009, 14:021009.

[65] Vlastos G, Verkooijen HM. Minimally invasive approaches for diagnosis and treatment of early-stage breast cancer. The oncologist, 2007, 12:1-10.

[66] Mirza AN, Fornage BD, Sneige N, Kuerer HM, Newman LA, Ames FC, Singletary SE. Radiofrequency ablation of solid tumors. Cancer journal, 2001, 7:95-102.

[67] Izzo F, Thomas R, Delrio P, Rinaldo M, Vallone P, DeChiara A, Botti G, D’Aiuto G, Cortino P, Curley SA. Radiofrequency ablation in patients with primary breast carcinoma: a pilot study in 26 patients. Cancer, 2001, 92:2036-44.

[68] Lim Z-ZJ, Li J-EJ, Ng C-T, Yung L-YL, Bay B-H Gold nanoparticles in cancer therapy. Acta pharmacologica Sinica, 2011, 32:983-90.

[69] Jain S, Hirst DG, O'Sullivan JM. Gold nanoparticles as novel agents for cancer therapy. The British journal of radiology, 2012, 85:101-113.

[70] Huang X, Jain PK, El-Sayed IH, El-Sayed MA. Gold nanoparticles: interesting optical properties and recent applications in cancer diagnostics and therapy. Nanomedicine, 2007, 2:681-693.

[71] Rippel RA, Seifalian AM. Gold revolution-gold nanoparticles for modern medicine and surgery. Journal of nanoscience and nanotechnology, 2011, 11:3740-3748.

[72] Lee S, Chon H, Lee M, Choo J, Shin SY, Lee YH, Rhyu IJ, Son SW, Oh CH. Surface-enhanced Raman scattering imaging of HER2 cancer markers overexpressed in single MCF7 cells using antibody conjugated hollow gold nanospheres. Biosensors \& bioelectronics, 2009, 24:2260-2263.

[73] Chattopadhyay N, Cai Z, Pignol J, Keller B, Lechtman E, Bendayan R, Reilly RM. Design and characterization of her-2-targeted gold nanoparticles for enhanced X-radiation treatment of locally advanced breast cancer. Mol. Pharmaceutics, 2010, 7(6):2194-2206.

[74] Chen L, Bouley D, Yuh E, D'Arceuil H, Butts K. Study of focused ultrasound tissue damage using MRI and histology. Journal of magnetic resonance imaging, 1999, 10:146-153.

[75] McDannold, Hynynen K, Wolf D, Wolf G, Jolesz F. MRI evaluation of thermal ablation of tumors with focused ultrasound. Journal of magnetic resonance imaging, 1998, 8:91-100. 
[76] Cline HE, Hynynen K, Watkins RD, Adams WJ, Schenck JF, Ettinger RH, Freund WR, Vetro JP, Jolesz FA. Focused US system for MR imaging-guided tumor ablation. Radiology, 1995, 194:731-737.

[77] Gianfelice D, Khiat A, Amara M, Belblidia A. Radiology MR imaging-guided focused us ablation of breast cancer: histopathologic assessment of effectiveness- initial. Radiology, 2002, 227(3):849-855.

[78] Kennedy JE. High-intensity focused ultrasound in the treatment of solid tumours. Nature reviews. Cancer, 2005, 5:321-327.

[79] Li Y-Y, Sha W-H, Zhou Y-J, Nie Y-Q. Short and long term efficacy of high intensity focused ultrasound therapy for advanced hepatocellular carcinoma. Journal of gastroenterology and hepatology, 2007, 22:2148-2154.

[80] Choi S-Y, Kim Y-S, Seo Y-J, Yang J, Choi K-S. Gas-filled phospholipid nanoparticles conjugated with gadolinium play a role as a potential theragnostics for MR-guided HIFU ablation. PloS one, 2012, 7:e34333.

[81] Theodorescu D. Cancer cryotherapy: evolution and biology. Rev Urol, 2004, 6 Suppl 4:S9-S19.

[82] Goel R, Anderson K, Slaton J, Schmidlin F, Vercellotti G, Belcher J, Bischof JC. Adjuvant approaches to enhance cryosurgery. Journal of biomechanical engineering, 2009, 131:074003.

[83] Sabel MS, Kaufman CS, Whitworth P, Chang H, Stocks LH, Simmons R, Schultz M. Cryoablation of early-stage breast cancer: work-in-progress report of a multi-institutional trial. Annals of surgical oncology, 2004, 11:542-549.

[84] Liu J, Deng Z-S. Nano-cryosurgery: advances and challenges. Journal of Nanoscience and Nanotechnology, 2009, 9:4521-4542.

[85] Shackley DC, Whitehurst C, Moore JV, Betts C. Photodynamic therapy. Journal of the royal society of medicine, 1999, 92(11): 562-565.

[86] Santosa V, Limantara L. Review photodynamic therapy: new light in medicine worlD. Indo. J. Chem, 2008, 8:279-291.

[87] Yoon J-H, Yoon H-E, Kim O, Kim SK, Ahn S-G, Kang KW. The enhanced anti-cancer effect of hexenyl ester of 5-aminolaevulinic acid photodynamic therapy in adriamycin-resistant compared to non-resistant breast cancer cells. Lasers in surgery and medicine, 2012, 44:76-86.

[88] Montazerabadi A-R, Sazgarnia A, Bahreyni-Toosi MH, Ahmadi A, Shakeri-Zadeh A, Aledavood A. Mitoxantrone as a prospective photosensitizer for photodynamic therapy of breast cancer. Photodiagnosis and photodynamic therapy, 2012, 9:46-51.

[89] Ahn T-G, Lee B-R, Choi E-Y, Kim DW, Han S-J. Photodynamic therapy for breast cancer in a BALB/c mouse model. Journal of gynecologic oncology, 2012, 23:115-119.

[90] Chatterjee DK, Fong LS, Zhang Y. Nanoparticles in photodynamic therapy: an emerging paradigm. Advanced drug delivery reviews, 2008, 60:1627-1637.

[91] Qian J, Wang D, Cai F, Zhan Q, Wang Y, He S. Photosensitizer encapsulated organically modified silica nanoparticles for direct two-photon photodynamic therapy and in vivo functional imaging. Biomaterials, 2012, 33:4851-4860.

[92] Jia X, Jia L. Nanoparticles improve biological functions of phthalocyanine photosensitizers used for photodynamic therapy. Current drug metabolism, 2012.

[93] Battah S, Balaratnam S, Casas A, O'Neill S, Edwards C, Batlle A, Dobbin P, MacRobert AJ. Macromolecular delivery of 5-aminolaevulinic acid for photodynamic therapy using dendrimer conjugates. Molecular cancer therapeutics, 2007, 6:876-85.

[94] Huang P, Lin J, Yang D, Zhang C, Li Z, Cui D. Photosensitizer-loaded dendrimer-modified multi-walled carbon nanotubes for photodynamic therapy. Journal of controlled release, 2011, 152 Suppl: e33-4.

[95] Stuchinskaya T, Moreno M, Cook MJ, Edwards DR, Russell DA. Targeted photodynamic therapy of breast cancer cells using antibody-phthalocyanine-gold nanoparticle conjugates. Photochemical \& photobiological sciences, 2011, 10:822-831.

[96] Kameyama N, Matsuda S, Itano O, Ito A, Konno T, Arai T, Ishihara K, Ueda M, Kitagawa Y. Photodynamic therapy using an anti-EGF receptor antibody complexed with verteporfin nanoparticles: a proof of concept study. Cancer biotherapy \& radiopharmaceuticals, 2011, 26:697-704. 
[97] Jang B, Park J, Tung C, Kim I, Choi Y. Gold nanorod-photosensitizer complex for near-infrared fluorescence imaging and photodynamic/photothermal therapy in vivo. ACS Nano, 2011, 5(2):1086-1094.

[98] Jang B, Choi Y. Photosensitizer-conjugated gold nanorods for enzyme-activatable fluorescence imaging and photodynamic therapy. Theranostics, 2012, 2:190-197.

[99] Kuo W-S, Chang C-N, Chang Y-T, Yang M-H, Chien Y-H, Chen S-J, Yeh C-S. Gold nanorods in photodynamic therapy, as hyperthermia agents, and in near-infrared optical imaging. Angewandte Chemie, 2010, 49:2711-2715.

[100] Kah JCY, Wan RCY, Wong KY, Mhaisalkar S, Sheppard CJR, Olivo M. Combinatorial treatment of photothermal therapy using gold nanoshells with conventional photodynamic therapy to improve treatment efficacy: an in vitro study. Lasers in surgery and medicine, 2008, 40:584-589.

[101] Day ES, Thompson P, Zhang L, Lewinski N, Ahmed N, Drezek R, Blaney SM, West JL. Nanoshellmediated photothermal therapy improves survival in a murine glioma model. Journal of neurooncology, 2011, 104:55-63.

[102] Young JK, Figueroa ER, Drezek R. Tunable nanostructures as photothermal theranostic agents. Annals of biomedical engineering, 2012, 40:438-459.

[103] Bernardi RJ, Lowery AR, Thompson PA, Blaney SM, West JL: Immunonanoshells for targeted photothermal ablation in medulloblastoma and glioma: an in vitro evaluation using human cell lines. Journal of neuro-oncology, 2008, 86:165-172.

[104] Gobin AM, Lee MH, Halas NJ, James WD, Drezek RA, West JL. Near-infrared resonant nanoshells for combined optical imaging and photothermal cancer therapy. Nano letters, 2007, 7:1929-1934.

[105] Gobin AM, Watkins EM, Quevedo E, Colvin VL, West L. Near infrared resonant gold/gold sulfide nanoparticles as a photothermal cancer therapeutic agent. Small, 2011, 6:745-752.

[106] Black KC, Yi J, Rivera JG, Zelasko-Leon DC, Messersmith PB. Polydopamine-enabled surface functionalization of gold nanorods for cancer cell-targeted imaging and photothermal therapy. Nanomedicine, 2012.

[107] Hong C. Photothermal therapy using $\mathrm{TiO}_{2}$ nanotubes in combination with near-infrared laser. Journal of Cancer Therapy, 2010, 01:52-58.

[108] Wang X, Wang C, Cheng L, Lee S-T, Liu Z. Noble metal coated single-walled carbon nanotubes for applications in surface enhanced Raman scattering imaging and photothermal therapy. Journal of the American Chemical Society, 2012, 134:7414-7422.

[109] Liang F, Chen B. A review on biomedical applications of single-walled carbon nanotubes. Current medicinal chemistry, 2010, 17:10-24.

[110] Liopo AV, Stewart MP, Hudson J, Tour JM, Pappas TC. Biocompatibility of native and functionalized single-walled carbon nanotubes for neuronal interface. Journal of nanoscience and nanotechnology, 2006, 6:1365-1374.

[111] von Maltzahn G, Park J-H, Agrawal A, Bandaru NK, Das SK, Sailor MJ, Bhatia SN. Computationally guided photothermal tumor therapy using long-circulating gold nanorod antennas. Cancer research, 2009, 69:3892-3900.

[112] Cai W. Applications of gold nanoparticles in cancer nanotechnology. Nanotechnology, Science and Applications, 2008, 1:17-32.

[113] Albanese A, Tang PS, Chan WCW. The effect of nanoparticle size, shape, and surface chemistry on biological systems. Annual review of biomedical engineering, 2012, 14:1-16.

[114] Mithun M. Shenoi, Neha B. Shah, Robert J. Griffin, Gregory M. Vercellotti and JC, Bischof Nanoparticle pre-conditioning for enhanced thermal therapies in cancer. Nanomedicine, 2011, 6:545-563.

[115] Buzea C, Pacheco II, Robbie K. Nanomaterials and nanoparticles: sources and toxicity. Biointerphases, 2007, 2:MR17-71. 
[116] Shukla R, Bansal V, Chaudhary M, Basu A, Bhonde RR, Sastry M. Biocompatibility of gold nanoparticles and their endocytotic fate inside the cellular compartment: a microscopic overview. Langmuir, 2005, 21:10644-10654.

[117] Pan Y, Neuss S, Leifert A, Fischler M, Wen F, Simon U, Schmid G, Brandau W, Jahnen-Dechent W. Size-dependent cytotoxicity of gold nanoparticles. Small, 2007, 3:1941-1949.

[118] Zhang X-D, Wu H-Y, Wu D, Wang Y-Y, Chang J-H, Zhai Z-B, Meng A-M, Liu P-X, Zhang L-A, Fan F-Y. Toxicologic effects of gold nanoparticles in vivo by different administration routes. International journal of nanomedicine, 2010, 5:771-781. 


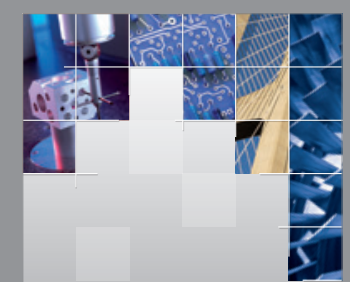

\section{Enfincering}
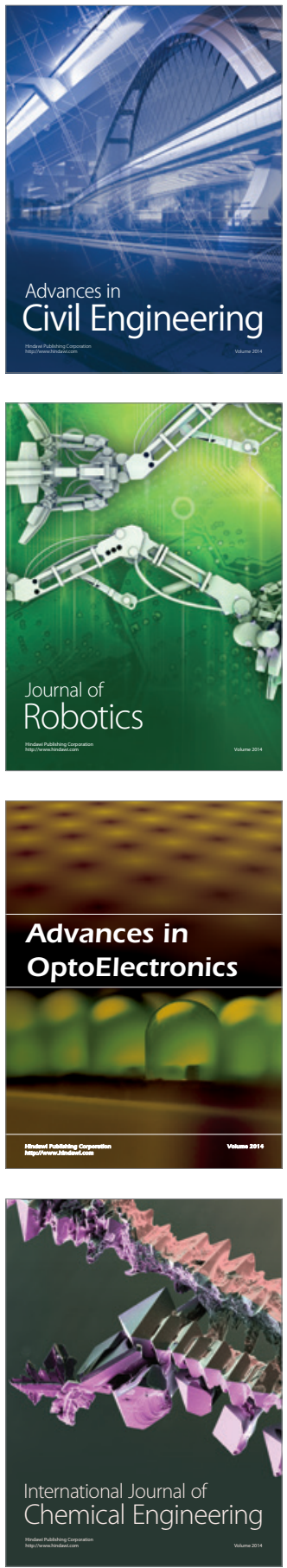

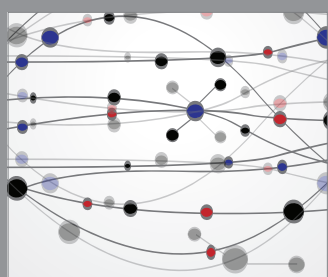

The Scientific World Journal

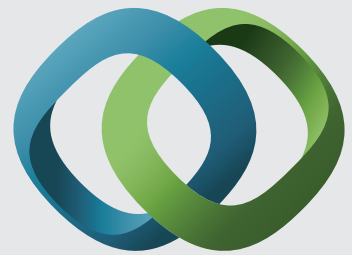

\section{Hindawi}

Submit your manuscripts at

http://www.hindawi.com
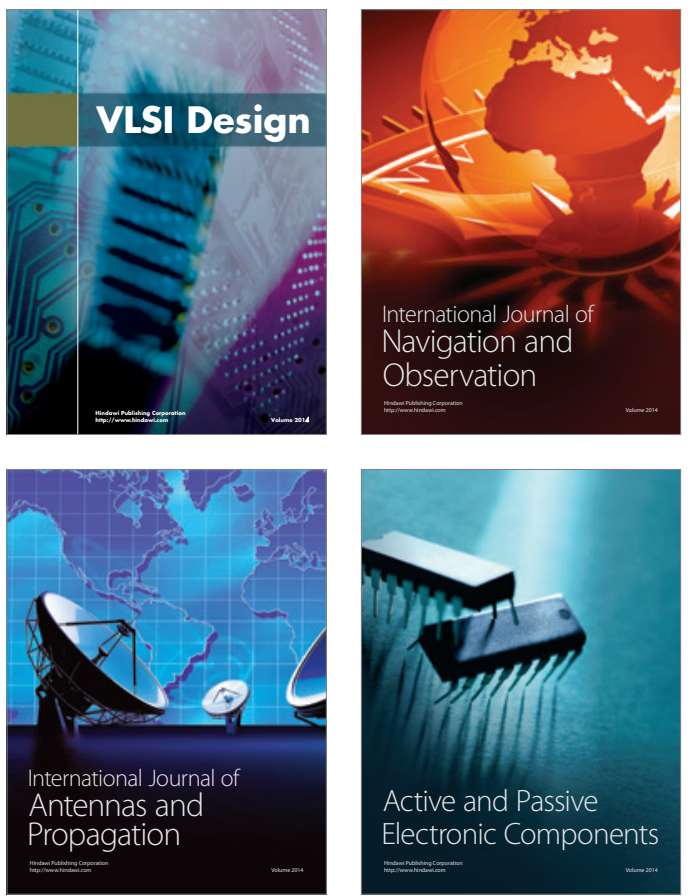
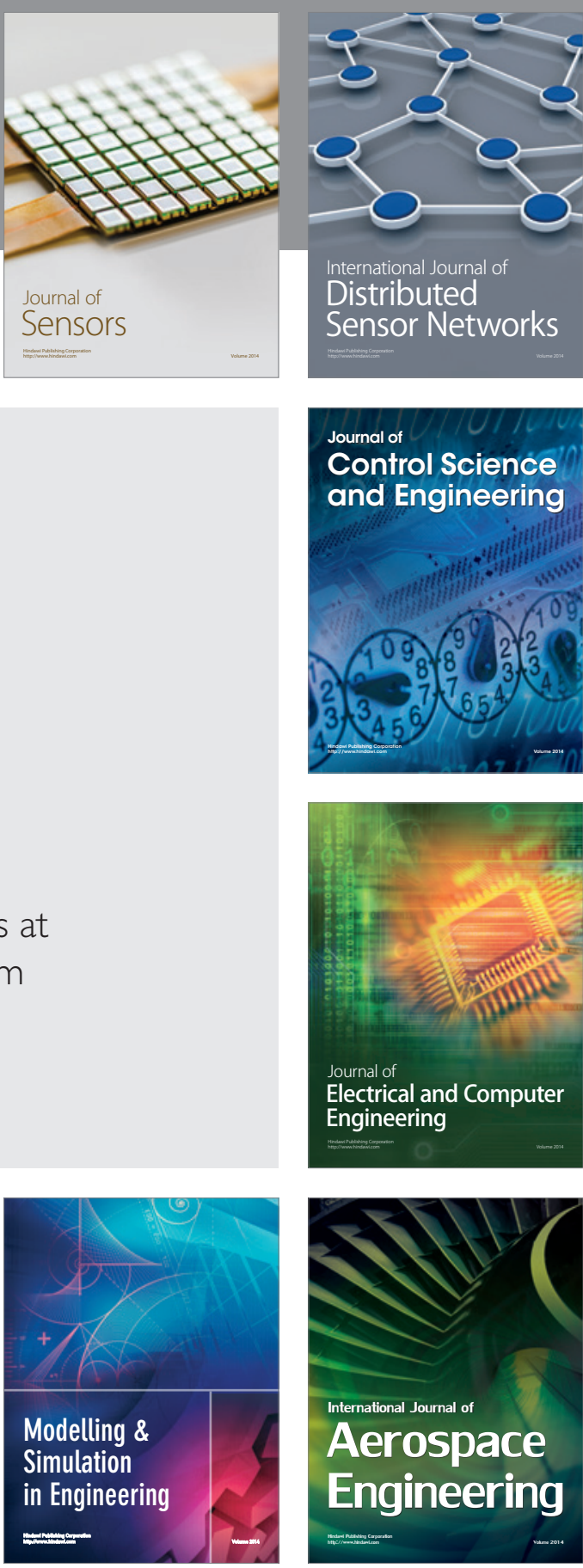

International Journal of

Distributed

Sensor Networks

Journal of

Control Science

and Engineering
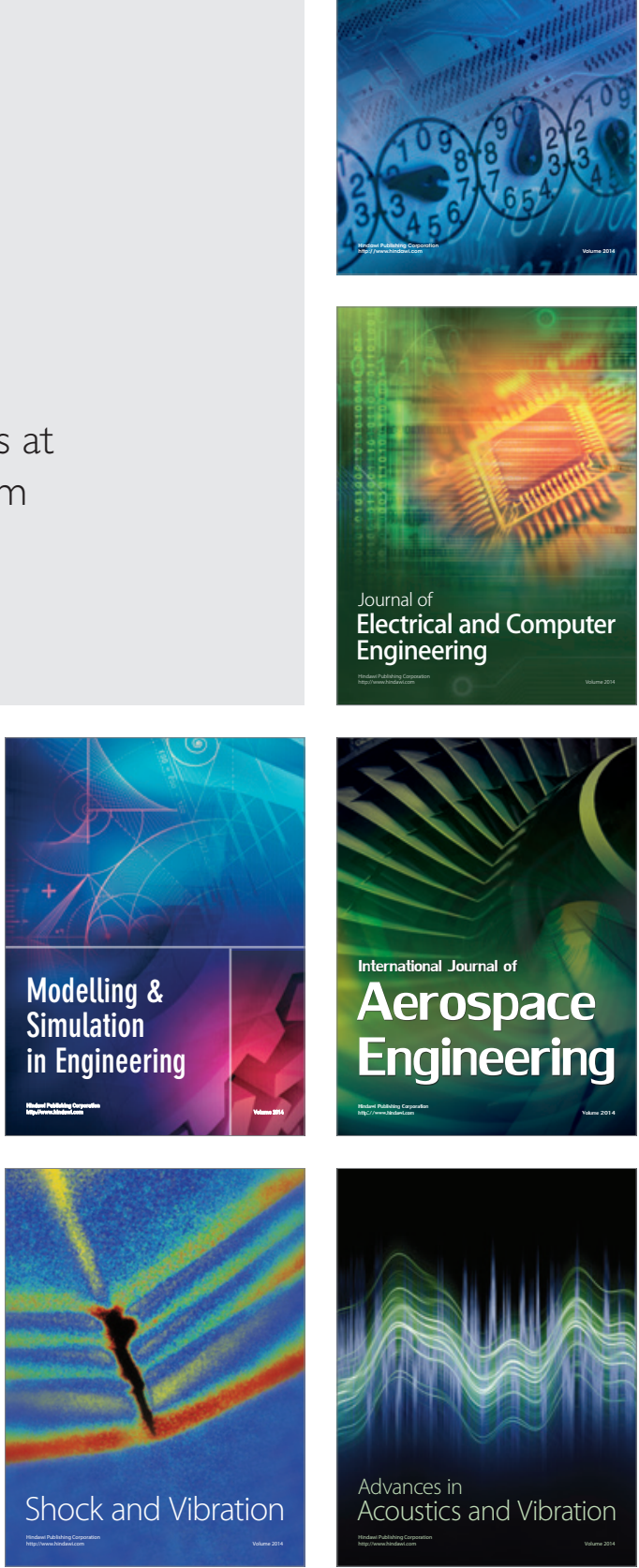